\title{
Almost Closed and Continuous Maps
}

\author{
Asha Gupta ${ }^{1}$, Kamal Kishore ${ }^{2}$ \\ ${ }^{1}$ ( Department of Applied Sciences, PEC University of Technology, Chandigarh, INDIA) \\ ${ }^{2}$ ( Department of Applied Sciences, PEC University of Technology, Chandigarh, INDIA)
}

\begin{abstract}
The primary purpose of this paper is to establish the relation between continuous maps and almost closed maps. In this endeavor some known results are improved.
\end{abstract}

Key Words: Almost closed, , almost compact, continuous, fibers, Frechet space.

AMS SUBJECT CLASSIFICATION CODES.54C05,54C10.

\section{Introduction}

By a space, we shall mean a topological space. No separation axioms are assumed and no map is assumed to be continuous or onto unless mentioned explicitly; $\operatorname{cl}(\mathrm{A})$ will denote the closure of the subset $\mathrm{A}$ in the space X. X is said to be Frechet space (or closure sequential in the terminology of Wilansky [1]) if for each subset $A$ of $X, x \in \operatorname{cl}(A)$ implies there exists a sequence $\left\{x_{n}\right\}$ in $A$ converging to $x$. If $X$ and $Y$ are topological spaces, we say that a map $\mathrm{f}: \mathrm{X} \rightarrow \mathrm{Y}$ has a closed graph if $\mathrm{G}(\mathrm{f})=\{(\mathrm{x}, \mathrm{f}(\mathrm{x})): \mathrm{x} \in \mathrm{X}\}$ is a closed subset of $\mathrm{Xx} \mathrm{Y}$. A map $\mathrm{f}: \mathrm{X} \rightarrow \mathrm{Y}$ is said to be almost closed if $\mathrm{f}(\mathrm{V})$ is closed for every regular closed subset $\mathrm{V}$ of $\mathrm{X}$. A space $\mathrm{X}$ is said to be almost compact if for every open cover $\left\{\mathrm{U}_{\alpha}: \alpha \in \Lambda\right\}$ there exists a finite subfamily $\left\{U_{\alpha_{i}}: \mathrm{i}=\right.$ $1,2, \ldots, \mathrm{n}\}$ such that $\bigcup_{i=1}^{n} \operatorname{cl}\left(U_{\alpha_{i}}\right)=\mathrm{X}$. If $\mathrm{f}: \mathrm{X} \rightarrow \mathrm{Y}$ is a map, then the fibers are the sets $\mathrm{f}^{-1}(\mathrm{y})$, where $\mathrm{y} \in \mathrm{Y}$. $\mathrm{X}$ is said to be B-W compact [2] if every infinite subset of $\mathrm{X}$ has at least one limit point .

The primary purpose of this paper is to give the relationship between almost closed maps and continuous maps. The following theorem 2.2 gives the conditions under which an almost closed map becomes continuous while theorem 2.4 gives the conditions under which a continuous map becomes almost closed. Moreover, some established results are improved.

In 1968,Fuller [3] has proved the following

Theorem 1.1[3,Corollary 3.9] .Let $\mathrm{f}: \mathrm{X} \rightarrow \mathrm{Y}$ be closed with closed fibers where $\mathrm{X}$ is regular. Then $\mathrm{f}$ has closed graph.

In 1997,Garg and Goel [4 ] have proved the following

Theorem 1.2 [4,Theorem 2]. Let $\mathrm{f}: \mathrm{X} \rightarrow \mathrm{Y}$ be closed with compact fibers where $\mathrm{X}$ is $\mathrm{T}_{2}$. Then $\mathrm{f}$ has closed graph.

Theorem 1.3[4, Theorem 4]. Let $\mathrm{f}: \mathrm{X} \rightarrow \mathrm{Y}$ have closed graph, then $\mathrm{f}$ is continuous if any one of the following conditions is satisfied.

(a) $\quad \mathrm{Y}$ is compact

(b) $\mathrm{X}$ is Frechet, $\mathrm{Y}$ is $\mathrm{B}-\mathrm{W}$ compact

(c) $\mathrm{f}$ is subcontinuous

Theorem 1.4[4, Theorem 7]. Let $\mathrm{f}: \mathrm{X} \rightarrow \mathrm{Y}$ be closed with(closed) compact fibers, where $\mathrm{X}$ is (regular) $\mathrm{T}_{2}$ and one of the conditions (a),(b),(c) in theorem 1.3 is satisfied. Then $\mathrm{f}$ is continuous.

\section{Main Results}

The following theorem 2.1 (theorem 2.2) is a generalisation of the above theorems 1.1 and theorem 1.2 (theorem 1.4) as the condition of closedness of $\mathrm{f}$ is weakened to almost closedness.

Theorem 2.1. Let $\mathrm{f}: \mathrm{X} \rightarrow \mathrm{Y}$ be almost closed with(closed) compact fibers, where $\mathrm{X}$ is (regular) $\mathrm{T}_{2}$. Then $\mathrm{f}$ has closed graph.

Proof. We prove the parenthesis part, the proof of the non parenthesis part is similar. Let $x \in X, y \in Y, y \neq$ $f(x)$. Then $x \notin f^{-1}(y)$ which is closed. Since $X$ is regular, there exist open sets $U_{x}$ and $U_{y}$ containing $x$ and $f^{-1}(y)$ respectively such that $U_{x} \cap U_{y}=\phi$ which implies $\operatorname{cl}\left(U_{x}\right) \cap U_{y}=\phi$. As $\quad f^{-1}(y) \subset U_{y}$ this implies $f^{-1}(y) \cap$ $\operatorname{cl}\left(\mathrm{U}_{\mathrm{x}}\right)=\phi$ and therefore $\mathrm{y} \notin \mathrm{f}\left(\mathrm{cl}\left(\mathrm{U}_{\mathrm{x}}\right)\right)$. Now $\mathrm{f}$ is almost closed map and $\mathrm{cl}\left(\mathrm{U}_{\mathrm{x}}\right)$ is a almost regular set implies 
$\mathrm{f}\left(\mathrm{cl}\left(\mathrm{U}_{\mathrm{x}}\right)\right)$ is a closed set. Hence $\mathrm{V}=\mathrm{Y}-\mathrm{f}\left(\mathrm{cl}\left(\mathrm{U}_{\mathrm{x}}\right)\right)$ is an open set containing $\mathrm{y}$ and $\mathrm{f}\left(\mathrm{U}_{\mathrm{x}}\right) \cap \mathrm{V}=\phi$ implying thereby that $\mathrm{f}$ has closed graph.

Combining our theorem 1.3 and above theorem 2.1, we obtain the following

Theorem 2.2. Let $\mathrm{f}: \mathrm{X} \rightarrow \mathrm{Y}$ be almost closed with(closed) compact fibers, where $\mathrm{X}$ is (regular) $\mathrm{T}_{2}$ and one of the conditions (a),(b),(c) in theorem 1.3 is satisfied. Then $\mathrm{f}$ is continuous.

The following lemma will be used in the proof of our theorem 2.4 which gives the conditions under which the converse of theorem 2.2 holds.

Lemma 2.1. Almost compact subset of a $T_{2}$ space is closed.

Proof. Let $\mathrm{K}$ be any almost compact subset of $\mathrm{T}_{2}$ space $\mathrm{X}$ and let $\mathrm{x} \notin \mathrm{K}$ which implies $\mathrm{x} \neq \mathrm{y}$,

$y \in K$. Then $X$ is $T_{2}$ implies there exist open sets $U_{x}$ and $U_{y}$ containing $x$ and $y$ respectively such that $U_{x} \cap U_{y}=$ $\phi$ and therefore $\mathrm{U}_{\mathrm{x}} \cap \mathrm{clU}_{\mathrm{y}}=\phi$. Now $\left\{\mathrm{U}_{\mathrm{y}}\right\}_{\mathrm{y}} \in \mathrm{K}$ is an open cover of $\mathrm{K}$ which is almost compact. Therefore, there exists a finite subfamily $\left\{U_{y_{i}}, i=1,2, \ldots n\right\}$ such that $\mathrm{K} \subset \bigcup_{i=1}^{n} \operatorname{cl}\left(U_{y_{i}}\right)$. Let $\mathrm{G}=\bigcap_{i=1}^{n} U_{x_{i}}$ Now $\mathrm{G}$ is an open set containing $\mathrm{x}$ and $\mathrm{G} \bigcap \mathrm{K}=\phi$ implying thereby that $\mathrm{x} \notin \mathrm{clK}$. Hence $\mathrm{K}$ is closed.

Theorem 2.3. Let $\mathrm{f}: \mathrm{X} \rightarrow \mathrm{Y}$ be continuous. Then image of every almost compact subset of $\mathrm{X}$ is almostcompact.

Proof. Let $\mathrm{K}$ be any almost-compact subset of $\mathrm{X}$. To prove $\mathrm{f}(\mathrm{K})$ is almost-compact, let $\left\{V_{\alpha}\right\}$ be any open cover of $\mathrm{f}(\mathrm{K})$. Then $\mathrm{f}^{-1}\left(V_{\alpha}\right)$ is an open cover of $\mathrm{K}$ which is almost compact. Therefore there exists a finite subfamily $\mathrm{f}$ ${ }^{1}\left(V_{\alpha_{i}}\right) \mathrm{i}=1,2,---\mathrm{n}$ such that $\mathrm{K}=\bigcup_{i=1}^{n} \operatorname{cl}\left(f^{-1} V_{\alpha_{i}}\right)$.

Now $\mathrm{f}(\mathrm{K})=\mathrm{f}\left(\bigcup_{i=1}^{n} \operatorname{cl}\left(f^{-1} V_{\alpha_{i}}\right)\right)=\bigcup_{i=1}^{n} f\left(c l\left(f^{-1}\left(V_{\alpha_{i}}\right)\right) \subset \bigcup_{i=1}^{n} \operatorname{cl}\left(V_{\alpha_{i}}\right)\right.$ as

$V_{\alpha_{i}} \subset \operatorname{cl}\left(V_{\alpha_{i}}\right), f^{-1}\left(V_{\alpha_{i}}\right) \subset f^{-1}\left(\operatorname{cl}\left(V_{\alpha_{i}}\right)\right) \Rightarrow \operatorname{cl} f^{-1}\left(V_{\alpha_{i}}\right) \subset f^{-1}\left(\operatorname{cl}\left(V_{\alpha_{i}}\right)\right)$ therefore $f\left(c^{-1} f^{-1}\left(V_{\alpha_{i}}\right)\right) \subset f\left(f^{-1}\left(c l\left(V_{\alpha_{i}}\right)\right)\right) \subset c l\left(V_{\alpha_{i}}\right)$.

Combining above lemma 2.1 and theorem 2.3, we get the following

Theorem 2.4. Let $f: X \rightarrow Y$ be continuous, where $X$ is almost compact and $Y$ is $T_{2}$. Then $f$ is almost closed.

Proof. The proof follows from above lemma 2.1 , theorem 2.3 and the fact that a regular closed subset of almost compact space is almost compact.

Combining theorems 1.3, 2.2 and 2.4 we get the following

Theorem 2.5. Let $f: X \rightarrow Y$ be any map with(closed) compact fibers, where $X$ is (regular) $T_{2}$ and almost compact, $\mathrm{Y}$ is $\mathrm{T}_{2}$ and one of the conditions (a),(b),(c) in theorem 1.3 is satisfied, then the following conditions (i) to (iii) are equivalent.

(i) $\mathrm{f}$ is continuous

(ii) $\mathrm{f}$ is almost closed

(iii) f has closed graph.

\section{References}

[1]. A. Wilansky, Topology for analysis Xerox College Publishing Lexington, Massachusetts, Toronto, 1970.

[2] . W.J. Thron, Topological Structures, Holt, Rinehart and Winston.1966.

[3]. R.V.Fuller, Relations among continuous and various non continuous functions, Pacific J. Math. 25, (1968)495-509.

[4]. Asha Goel \& G.L. Garg, On Maps:Continuous,Closed, Perfect, and with Closed Graph, International Journal of Mathematics \& Maths. Sciences, Florida, USA, Vol. 20, No. 2(1997) 405-408. 